\title{
Renal effects of dexmedetomidine during coronary artery bypass surgery: a randomized placebo-controlled study
}

\author{
Kari Leino ${ }^{1 *}$, Markku Hynynen², Jouko Jalonen ${ }^{1}$, Markku Salmenperä ${ }^{3}$, Harry Scheinin ${ }^{4}$, Riku Aantaa ${ }^{1}$ and for \\ the Dexmedetomidine in Cardiac Surgery Study Group
}

\begin{abstract}
Background: Dexmedetomidine, an alpha 2 -adrenoceptor agonist, has been evaluated as an adjunct to anesthesia and for the delivery of sedation and perioperative hemodynamic stability. It provokes dose-dependent and centrally-mediated sympatholysis. Coronary artery bypass grafting (CABG) with extracorporeal circulation is a stressful procedure increasing sympathetic nervous system activity which could attenuate renal function due the interrelation of sympathetic nervous system, hemodynamics and renal function. We tested the hypothesis that dexmetomidine would improve kidney function in patients undergoing elective CABG during the first two postoperative days.

Methods: This was a double-blind, randomized, parallel-group study. Patients with normal renal function and scheduled for elective CABG were randomized to placebo or to infusion of dexmedetomidine to achieve a pseudo steady-state plasma concentration of $0.60 \mathrm{ng} / \mathrm{ml}$. The infusion was started after anesthesia induction and continued until $4 \mathrm{~h}$ after surgery. The primary endpoint was creatinine clearance. Other variables included urinary creatinine and output, fractional sodium and potassium excretion, urinary potassium, sodium and glucose, serum and urinary osmolality and plasma catecholamine concentrations. The data were analyzed with repeated-measures ANOVA or Cochran-Mantel-Haenszel test.
\end{abstract}

Results: Sixty-six of 87 randomized patients were evaluable for analysis. No significant between-group differences were recorded for any indices of renal function except for a mean $74 \%$ increase in urinary output with dexmedetomidine in the first $4 \mathrm{~h}$ after insertion of a urinary catheter $(p<0.001)$. Confidence interval examination revealed that the sample size was large enough for the no-difference statement for creatinine clearance.

Conclusions: Use of intravenous dexmedetomidine did not alter renal function in this cohort of relatively low-risk elective CABG patients but was associated with an increase in urinary output.

This study was carried out in 1994-1997 and was thus not registered.

\section{Background}

Perioperative administration of alpha ${ }_{2}$-adrenergic agonist dexmedetomidine, has been shown to reduce anesthetic requirements, enhance hemodynamic stability and provide sedation during postoperative recovery following coronary artery bypass and other surgery [1-6]. Acute kidney injury (AKI) is a recognized complication of

\footnotetext{
* Correspondence: kari.leino@tyks.fi

'Department of Anaesthesiology, Intensive Care, Emergency Care and Pain Medicine, Turku University Hospital, Turku, Finland

Full list of author information is available at the end of the article
}

cardiovascular surgery and one associated with high mortality and costs-of-care [7]. The pathogenesis of AKI is multifactorial and involves hemodynamic, inflammatory and nephrotoxic components [7]. It is also known that hemodynamics, sympathetic nervous system activity and renal function are tightly interrelated. Since cardiac surgery is associated with activation of sympathetic nervous system [3], dexmedetomidine-induced sympatholysis might attenuate harmful hemodynamic events resulting in prevention of AKI. In fact, alpha ${ }_{2}$-adrenoceptor activation does produce some potentially renal-

\section{Biomed Central}

(c) 2011 Leino et al; licensee BioMed Central Ltd. This is an Open Access article distributed under the terms of the Creative Commons Attribution License (http://creativecommons.org/licenses/by/2.0), which permits unrestricted use, distribution, and reproduction in any medium, provided the original work is properly cited. 
protective effects including inhibition of renin release, increased glomerular filtration and increased secretion of sodium and water $[8,9]$. Moreover, pretreatment with clonidine, the archetype of alpha ${ }_{2}$-adrenergic agonists, has shown beneficial renal effects after cardiac surgery [10]. In an earlier study we found that urine output tended to be greater in patients receiving dexmedetomidine than in those receiving placebo in post-coronary artery bypass grafting (CABG) patients [3].

To date, no single pharmacological regimen has conclusively proved its efficacy in preventing AKI [7] and any potential means to decrease the number of cardiac surgery patients encountering this deleterious adverse effect should be sought. We conducted a study to test the hypothesis that dexmedetomidine could protect kidney function in patients undergoing CABG with extracorporeal circulation (ECC). This study reports renal effects of dexmedetomidine compared to placebo.

\section{Methods}

This was a double-blind, randomized, parallel-group study designed to compare dexmedetomidine, administered as a continuous intravenous (i.v.) infusion at rates needed to achieve a pseudo steady-state plasma concentration of $0.60 \mathrm{ng} / \mathrm{ml}$, with placebo in terms of renal effects. Altogether 93 patients were screened and 87 were randomized to receive the study treatment (Figure 1) in two study centers, Helsinki and Turku University Hospitals. Selection of the target concentration for dexmedetomidine was based on previous experience in CABG patients [3].

The study was performed according to Helsinki Declaration and standards of Good Clinical Practise. The protocol and amendments were reviewed and approved by separate Ethics Committees of Turku and Helsinki Universities and the Finnish Medicines Agency. All patients provided written informed consent. Adult (aged > 21 years) patients undergoing scheduled elective CABG surgery at the two study centers were candidates for inclusion in the study if they had normal renal function and serum creatinine $(\mathrm{S}-\mathrm{Crea})<115 \mu \mathrm{mol} / \mathrm{l}$, were of American Society of Anesthesiologists (ASA) physical status III or IV, and met the general participation criteria for the study. Patients were not admitted to the study if they had left main coronary artery occlusion > $50 \%$, valvular dysfunction necessitating operation, hemodynamically significant arrhythmia, or left ventricular ejection fraction $<40 \%$. Other exclusion conditions included: treatment with angiotensin-converting enzyme inhibitors or diuretics; use of alpha $a_{2}$-agonists to treat

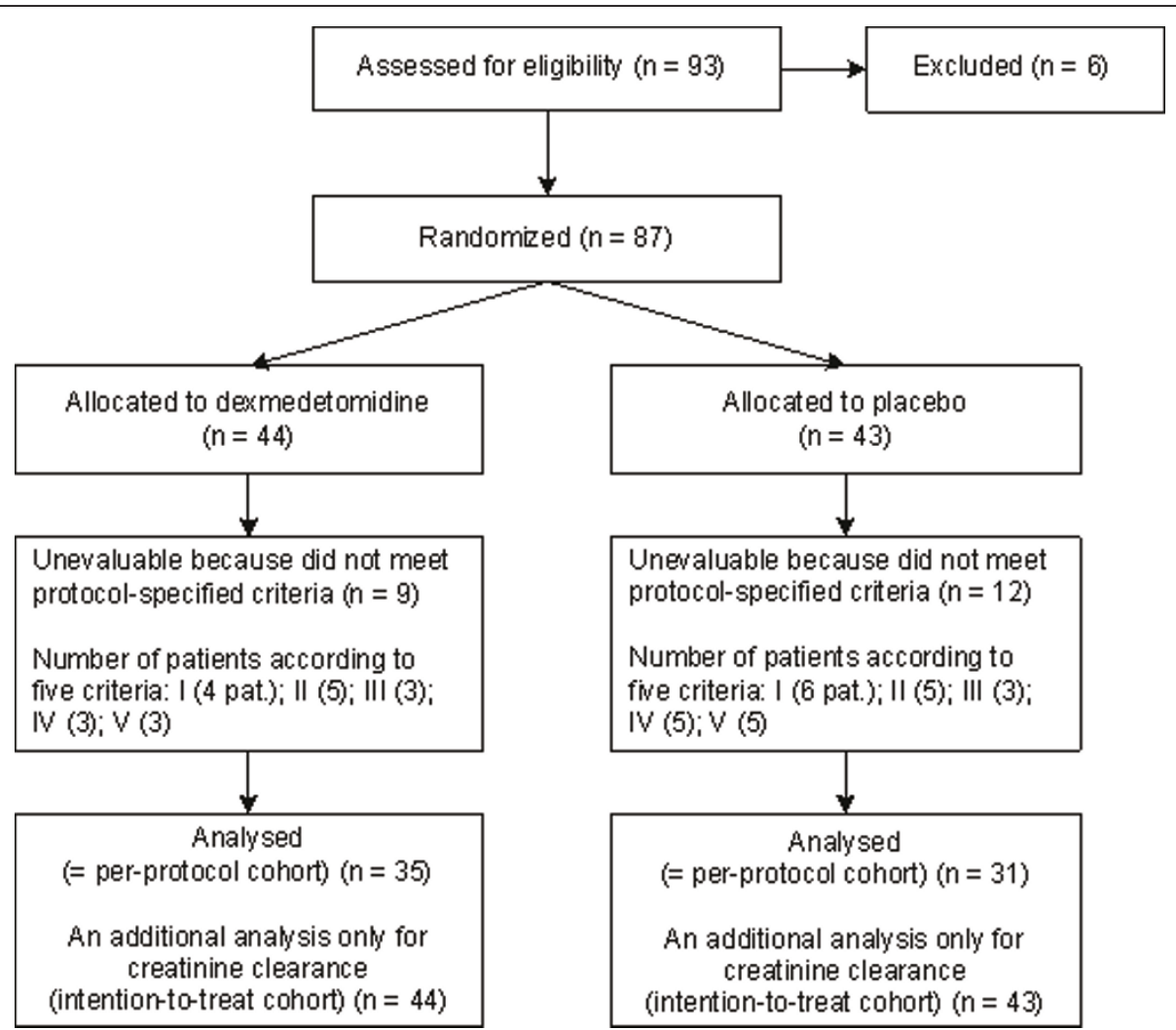

Figure 1 Summary of patient disposition 
hypertension; untreated hypertension; cerebrovascular disease; type 1 diabetes mellitus or diabetes insipidus; morbid obesity; evidence or suspicion of abnormal liver function due to drug abuse or alcoholism; a history of severe allergy to drugs; and previous exposure to dexmedetomidine. Pregnant or breastfeeding women were ineligible, as were women of childbearing age not using reliable contraceptive methods. Randomization was performed by an independent statistician using random permuted blocks of 10 patients within each center. Both centers were provided with indistinguishable ampoules of dexmedetomidine and placebo to be allotted in numerical order to consecutive patients enrolled by study physicians. All patients, personnel and investigators including the persons responsible for data management and statistics were blinded to the treatment assignment. The code was opened only after recruitment and data collection of all study patients had been completed.

\section{Study outline and measurements}

All patients received zopiclone $7.5 \mathrm{mg}$ orally the night before surgery. Oral lorazepam 4-6 mg was administered $2 \mathrm{~h}$ before induction of anesthesia.

Patients were instrumented upon arrival in the operating theater, including the introduction of a pulmonary artery catheter. Ringer's acetate was infused intravenously at $10 \mathrm{ml} \cdot \mathrm{kg}^{-1} \cdot \mathrm{h}^{-1}$ until commencement of ECC. Baseline hemodynamic and blood chemistry measurements were obtained after at least 5 min of stabilisation after catheterisation. Anesthesia was induced with $30 \mu \mathrm{g} / \mathrm{kg}$ fentanyl given as a 5-min i.v. infusion and coadministered with i.v. lorazepam $2 \mathrm{mg}$. Pancuronium 0.1 $\mathrm{mg} / \mathrm{kg}$ was then administered i.v. and a urinary catheter introduced. All urine passed during the $48 \mathrm{~h}$ after catheter insertion was collected.

Study drug infusion was commenced immediately after anesthesia induction, and continued until $4 \mathrm{~h}$ after arrival in the intensive care unit (ICU). To reach and maintain a constant pseudo steady-state plasma concentration of $0.60 \mathrm{ng} / \mathrm{ml}$ of dexmedetomidine a five-step infusion of $4.0 \mu \mathrm{g} / \mathrm{ml}$ dexmedetomidine or placebo with the following decreasing infusion rates was used: 39.0 $\mathrm{ml} / \mathrm{h}$ for $20 \mathrm{~min}, 24.5 \mathrm{ml} / \mathrm{h}$ for $40 \mathrm{~min}, 14.0 \mathrm{ml} / \mathrm{h}$ for 60 $\mathrm{min}, 10.5 \mathrm{ml} / \mathrm{h} 120 \mathrm{~min}$ and $7.0 \mathrm{ml} / \mathrm{h}$ from that on. The dosing was based on our previous experience with dexmedetomidine in CABG patients [3] and simulation with data available from Talke et al. [11].

CABG was performed under ECC using moderate systemic hypothermia (nasopharyngeal temperature $30^{\circ} \mathrm{C}$ ), a standardized protocol and mannitol $150 \mathrm{mg} / \mathrm{ml} 100$ $\mathrm{ml}$ added to ECC priming. ECC was initiated at a flow rate of $2.41 \mathrm{~min}^{-1} \cdot \mathrm{m}^{-2}$ and reduced to $1.81 \mathrm{~min}^{-1} \cdot \mathrm{m}^{-2}$ during hypothermia. Cold crystalloid potassium cardioplegic solution was used as required to maintain asystole.

Intraprocedural anaesthesia was maintained with fentanyl $0.1 \mu \mathrm{g} \cdot \mathrm{kg}^{-1} \cdot \mathrm{min}^{-1}$ until rewarming (rectal temperature $35^{\circ} \mathrm{C}$ ). Isoflurane was administered into the perfusion unit at an inspiratory concentration of $0.2 \%$. Patients were ventilated with $40-60 \%$ oxygen in air with a target arterial $\mathrm{CO}_{2}$ tension of $35-45 \mathrm{mmHg}$ (not corrected to the patient's temperature) and oxygen saturation $\left(\mathrm{SaO}_{2}\right)>95 \%$. Fentanyl and isoflurane were discontinued after skin closure.

Cardiovascular parameters and clinical signs were used as indicators of anesthetic depth. Specific provisions and interventions were developed in the study protocol to maintain a sufficient level of anesthesia and acceptable hemodynamics, to prevent tachycardia, bradycardia, hypertension or hypotension lasting $1 \mathrm{~min}$ or more and manage low urinary output intraoperatively and postoperatively. These criteria and the respective therapeutic interventions are summarized in table 1 . Deviations in other hemodynamic parameters were dealt with as a part of standard clinical practice. Post-CABG, patients were transferred to the ICU, where they were ventilated and weaned from respirator according to standard ICU protocols.

\section{Creatinine clearance}

The primary endpoint of the study was renal function assessed by determination of creatinine clearance at 12$24 \mathrm{~h}$ prior to surgery, and $0-24 \mathrm{~h}$ and $24-48$ after urinary catheter insertion after induction of anesthesia. Creatinine clearance was defined as (U-Crea) $\times$ (urine output)/S-Crea, where U-Crea and S-Crea represent urinary and serum creatinine, respectively.

\section{Other variables of renal function}

Creatinine clearance from $30 \mathrm{~min}$ urine output at 4-h intervals was quantified. Cumulative and 4-hourly urinary output was examined. Fractional sodium excretion (dU-Na) and fractional potassium excretion (dU-K) were determined at the same time as creatinine clearance. Urine samples for determination of urinary potassium (U-K), urinary sodium (U-Na), U-Crea, urinary glucose (U-Gluc) and urinary osmolality (U-Osmol) were taken after urinary catheter insertion, 1 min after aortic cross clamp removal and 24 and $48 \mathrm{~h}$ after urinary catheter insertion. In addition samples for determination of $U$ $\mathrm{Na}$ and $\mathrm{U}-\mathrm{Crea}$ were taken at $4 \mathrm{~h}$ intervals until $24 \mathrm{~h}$ from catheter insertion.

\section{Plasma cathecolamines}

Plasma epinephrine and norepinephrine concentrations were determined using high-performance liquid chromatography with coulometric detection [12]. 
Table 1 Protocol-specified intraoperative and postoperative interventions for maintenance of hemodynamic and anesthetic stability, and correction of low urinary output

\begin{tabular}{|c|c|c|}
\hline \multicolumn{3}{|l|}{ Tachycardia* } \\
\hline Before ECC & $\mathrm{HR}>90$ beats $/ \mathrm{min}$ & Esmolol in increments of $0.5 \mathrm{mg} / \mathrm{kg}$ i.v. \\
\hline After ECC & $\mathrm{HR}>110$ beats/min & As above \\
\hline In the ICU & $\mathrm{HR}>120$ beats/min & $\begin{array}{l}\text { Esmolol } 0.5 \mathrm{mg} / \mathrm{kg} \text { i.v. If HR decreased }<120 \text { beats } / \mathrm{min} \text {, give } \\
\text { metoprolol } 1-5 \mathrm{mg} \text { i.v. }\end{array}$ \\
\hline \multicolumn{3}{|l|}{ Bradycardia } \\
\hline Before ECC & $\mathrm{HR}<40$ beats $/ \mathrm{min}$ & Glycopyrrolate 0.2 mg i.v. \\
\hline After ECC & $\mathrm{HR}<70$ beats $/ \mathrm{min}$ & As above \\
\hline In the ICU & $\mathrm{HR}<60$ beats/min & Pacing at 70 beats/min \\
\hline \multicolumn{3}{|l|}{ Hypertension** } \\
\hline Before ECC & $\mathrm{SAP}>150 \mathrm{mmHg}$ & $\begin{array}{l}\text { Increase ET-IF by } 0.4 \% \text { and administer } 50 \mu \mathrm{g} \text { i.v. bolus of glyceryl } \\
\text { trinitrate. If response not adequate within } 4 \text { min, increase ET-IF a } \\
\text { further } 0.4 \% \text { and give } 5 \mu \mathrm{g} / \mathrm{kg} \text { i.v. bolus of fentanyl. If still not adequate, } \\
\text { increase ET-IF by } 0.4 \% \text { and give } 50 \mu \mathrm{g} \text { i.v. bolus of glyceryl trinitrate. } \\
\text { Taper isoflurane (to } 0.2 \% \text { ET-IF) when SAP and HR have reached } \\
\text { predetermined values with no clinical signs of insufficient anaesthesia. } \\
\text { If SAP or HR rises again, increase ET-IF by } 0.4 \% \text { and give } 50 \mu \mathrm{g} \text { i.v. } \\
\text { glyceryl trinitrate. }\end{array}$ \\
\hline During ECC & MAP > $80 \mathrm{mmHg}$ & As above \\
\hline After ECC & $\mathrm{SAP}>130 \mathrm{mmHg}$ & As above \\
\hline In the ICU & $\mathrm{SAP}>150 \mathrm{mmHg}$ & Start glyceryl trinitrate infusion to effect. \\
\hline \multicolumn{3}{|l|}{ Hypotension } \\
\hline Before ECC & $\mathrm{SAP}<90 \mathrm{mmHg}$ & $\begin{array}{l}\text { Reduce ET-IF } 0.4 \% \text { per } 4 \text { min until ET-IF } 0.2 \% \text {. If not sufficient to restore } \\
\text { SAP, administer ephedrine } 2.5 \mathrm{mg} \text { i.v. bolus. If SAP response still not } \\
\text { adequate repeat ephedrine bolus plus } 250 \mathrm{ml} \text { i.v. bolus of } \\
\text { hydroxyethylstarch (or } 500 \mathrm{ml} \text { of Ringer's acetate). } \\
\text { If necessary, repeat this intervention once, } 4 \text { min after first } \\
\text { administration. If SAP response still not adequate, start epinephrine } \\
\text { infusion at } 0.03 \mu \mathrm{g} \cdot \mathrm{kg}-1 \cdot \text { min-1; titrate to maximum of } 0.3 \mu \mathrm{\mu g} \cdot \mathrm{kg}-1 \text {. } \\
\text { h-1. Taper epinephrine when SAP remains within protocol-specified } \\
\text { values. }\end{array}$ \\
\hline During ECC & $\mathrm{MAP}<30 \mathrm{mmHg}$ & i.v. bolus doses of phenylephrine $(0.2 \mathrm{mg})$ \\
\hline After ECC & $\mathrm{SAP}<80 \mathrm{mmHg}$ & As for 'Before ECC' \\
\hline In the ICU & $\mathrm{SAP}<90 \mathrm{mmHg}$ & $\begin{array}{l}250 \mathrm{ml} \text { i.v. bolus of hydroxyethylstarch (or } 500 \mathrm{ml} \text { of Ringer's acetate) } \\
\text { over } 10 \mathrm{~min} \text {. If effective, repeat. Otherwise start epinephrine at a rate of } \\
3 \mu \mathrm{g} \cdot \mathrm{kg}^{-1} \cdot \mathrm{min}-1\end{array}$ \\
\hline $\begin{array}{l}\text { Clinical signs of } \\
\text { light anaesthesia }\end{array}$ & $\begin{array}{l}\text { E.g. bucking, lacrimation, sweating, movement, eye } \\
\text { opening, grimacing }\end{array}$ & As for management of hypertension \\
\hline \multicolumn{3}{|c|}{ Low urinary output } \\
\hline Before ECC & $\begin{array}{l}\text { Urinary output }<1 \mathrm{ml} \cdot \mathrm{kg}^{-1} \cdot \mathrm{h}-1 \text { during a } 30 \mathrm{~min} \\
\text { period, when SAP above threshold for hypotension }\end{array}$ & $\begin{array}{l}250 \mathrm{ml} \text { i.v. bolus of hydroxyethylstarch (or } 500 \mathrm{ml} \text { of Ringer's acetate) } \\
\text { over } 10 \mathrm{~min} \text {. If response not sufficient, repeat twice. } \\
\text { If response not sufficient } 15 \mathrm{~min} \text { after third bolus, administer } \\
\text { furosemide } 5 \mathrm{mg} \text { i.v. every } 30 \mathrm{~min} \text { until effect is produced }\end{array}$ \\
\hline During ECC & $\begin{array}{l}\text { Urinary output }<1 \mathrm{ml} \cdot \mathrm{kg}^{-1} \cdot \mathrm{h}-1 \text { during a } 30 \mathrm{~min} \\
\text { period, MAP }>30 \mathrm{mmHg}\end{array}$ & $\begin{array}{l}\text { Phenylephrine } 0.2 \mathrm{mg} \text { i.v. bolus dose, repeated up to } 3 \text { times until MAP } \\
\geq 50 \mathrm{mmHg} \text {. } \\
\text { If urinary response not sufficient despite MAP } \geq 50 \mathrm{mmHg} \text { for } 30 \mathrm{~min} \text {, } \\
\text { administer furosemide } 5 \mathrm{mg} \text { i.v. every } 30 \mathrm{~min} \text { until effect is produced }\end{array}$ \\
\hline After ECC & As for 'Before ECC' & As for 'Before ECC' \\
\hline In the ICU & Urinary output $<1 \mathrm{ml} \cdot \mathrm{kg}-1 \cdot \mathrm{h}-1$ & $\begin{array}{l}250 \mathrm{ml} \text { i.v. bolus of hydroxyethylstarch (or } 500 \mathrm{ml} \text { of Ringer's acetate) } \\
\text { over } 10 \mathrm{~min} \text {. If response not sufficient, give furosemide } 5 \mathrm{mg} \text { i.v. at } 30 \\
\text { min intervals }\end{array}$ \\
\hline
\end{tabular}

*Without hypertension; ** with or without tachycardia or clinical signs of inadequate anaesthesia. ECC = extracorporeal circulation; HR = heart rate; $\mathrm{ET}-\mathrm{IF}=$ end-tidal concentration of isoflurane; ICU = intensive care unit, MAP = mean arterial pressure; SAP = systolic arterial pressure.

\section{Statistical analyses}

Forty patients per treatment group were needed to get a $80 \%$ power to detect a $35 \%$ difference between the treatment groups with a 5\% (two-sided) type I error rate and assuming a standardized effect size (expected effect size divided by SD of the outcome variable) of 0.63. Assuming a $10 \%$ drop-out rate, the final sample size was set at 88 patients (44/group). 
The analysis of renal function was based on patients meeting the following five criteria of evaluation: (i) study drug infusion commenced within 30 min after anesthesia induction and continued intraoperatively and 2-4 h postoperatively; (ii) preoperative and one other perioperative $24 \mathrm{~h}$ creatinine clearance value obtained; (iii) no reoperation during the study period; (iv) no development of myocardial dysfunction requiring inotropes or intra-aortic balloon pump support; and (v) extubation within $24 \mathrm{~h}$ post-CABG. A supplementary analysis of creatinine clearance was also carried out, based on the intention-to-treat (ITT) population of 87 patients.

Creatinine clearance was analyzed using repeatedmeasures ANOVA with treatment and center as grouping factors and time as a within factor. Perioperative $\mathrm{dU}-\mathrm{Na}$, total and cumulative urine volume, S-Crea, UCrea, serum and urinary electrolytes (serum potassium $[\mathrm{S}-\mathrm{K}]$, serum sodium $[\mathrm{S}-\mathrm{Na}]$, urinary potassium $[\mathrm{U}-\mathrm{K}]$, urinary sodium [U-Na serum and urinary osmolarity (SOsmol, U-Osmol) and blood glucose were examined in a similar way. The Cochran-Mantel-Haenszel (CMH) test was used for urinary glucose, requirement, plasma catecholamines and requirements for postoperative cardiac pacing.

\section{Results}

The study was carried out in years 1994-1997 and prematurely terminated due to slow recruitment rate towards the end of the study. After opening the study code it turned out that a total of 93 Caucasian patients had been screened for eligibility, of which 87 had been randomized: 44 to receive dexmedetomidine and 43 to receive placebo. Twenty-one of the randomized patients (dexmedetomidine, $\mathrm{n}=9$; placebo, $\mathrm{n}=12$ ) did not fulfill the evaluation criteria. Analysis of creatinine clearance was thus based on 66 evaluable patients (dexmedetomidine, $\mathrm{n}=35$; placebo, $\mathrm{n}=31$ ). The disposition of patients is illustrated in figure 1.

Table 2 summarizes demographic and other baseline characteristics of the evaluable patients $(n=66)$ in the two study groups. There were no significant differences between the groups regarding concurrent and preoperative cardiac medications, baseline laboratory data, duration of anesthesia during CABG, time to extubation or duration of study drug infusion. Mean artery pressure (MAP) was $86 \pm 9 \mathrm{mmHg}$ in the dexmedetomidine group and $82 \pm 8 \mathrm{mmHg}$ in the placebo group (p = $0.015)$ prior to ECC. During ECC MAP was $55 \pm 7$ $\mathrm{mmHg}$ and $58 \pm 8 \mathrm{mmHg}(\mathrm{p}=0.064)$ in dexmedetomidine and placebo groups, respectively. After ECC until admission to ICU MAP was $68 \pm 6 \mathrm{mmHg}$ in the dexmedetomidine group and $73 \pm 9 \mathrm{mmHg}(\mathrm{p}=0.019)$ in the placebo group. Postoperatively systolic blood
Table 2 Patient demographics, operation data and baseline hemodynamics

\begin{tabular}{|c|c|c|}
\hline & $\begin{array}{c}\text { Dexmedetomidine } \\
(\mathrm{n}=35)\end{array}$ & $\begin{array}{l}\text { Placebo } \\
(\mathrm{n}=31)\end{array}$ \\
\hline Men & 31 & 28 \\
\hline Women & 4 & 3 \\
\hline Age (years) & $59.5 \pm 8.5$ & $62.4 \pm 7.0$ \\
\hline Weight (kg) & $83.7 \pm 11.9$ & $79.7 \pm 8.7$ \\
\hline Body surface area $\left(\mathrm{m}^{2}\right)$ & $1.97 \pm 0.17$ & $1.92 \pm 0.11$ \\
\hline Systolic blood pressure $(\mathrm{mmHg})$ & $142 \pm 21$ & $138 \pm 21$ \\
\hline Diastolic blood pressure (mmHg) & $73 \pm 11$ & $71 \pm 9$ \\
\hline Heart rate (beats/min) & $61 \pm 13$ & $60 \pm 7$ \\
\hline \multicolumn{3}{|l|}{ ASA grade } \\
\hline III & 2 & 0 \\
\hline IV & 33 & 31 \\
\hline \multicolumn{3}{|l|}{ NYHA classification } \\
\hline$\|$ & 12 & 12 \\
\hline III & 22 & 17 \\
\hline IV & 1 & 2 \\
\hline Operation time (min) & $213 \pm 55$ & $190 \pm 38$ \\
\hline Perfusion time (min) & $107 \pm 29$ & $96 \pm 22$ \\
\hline Number of grafts & $3 \pm 0.7$ & $3 \pm 0.6$ \\
\hline Time to extubation (min) & $1114 \pm 248$ & $1193 \pm 283$ \\
\hline
\end{tabular}

Data are presented as number of subjects or mean \pm SD. Data are based on the per-protocol cohort $(n=66)$. ASA = American Society of Anesthesiologists; NYHA $=$ New York Heart Association.

pressure was measured instead of MAP up to $24 \mathrm{~h}$ from admission to ICU being $109 \pm 10 \mathrm{mmHg}$ and $111 \pm 10$ $\mathrm{mmHg}(\mathrm{p}=0.44)$ in dexmedetomidine and placebo groups, respectively. The total volume of intraoperative Ringer's acetate administered was $5215 \pm 913 \mathrm{ml}$ in the dexmedetomidine group and $4996 \pm 1105 \mathrm{ml}(\mathrm{p}=0.21)$ in the placebo group. The postoperative volumes of Ringer's acetate in the ICU up to 24 h from urinary catheter insertion were $2942 \pm 1084 \mathrm{ml}$ and $2958 \pm$ $1037 \mathrm{ml}(\mathrm{p}=0.41)$ in dexmedetomidine and placebo groups, respectively. The intraoperative hydroxyethyl starch volumes were $344 \pm 309 \mathrm{ml}$ and $419 \pm 440 \mathrm{ml}(\mathrm{p}$ $=0.97)$ and postoperatively $1064 \pm 385 \mathrm{ml}$ and $968 \pm$ $451 \mathrm{ml}(\mathrm{p}=0.47)$ in dexmedetomidine and placebo groups, respectively. The average blood loss during the first $16 \mathrm{~h}$ after CABG was $1104 \pm 376 \mathrm{ml}$ with dexmedetomidine and $904 \pm 307 \mathrm{ml}$ with placebo $(\mathrm{p}=0.023)$. Twenty-five patients in both groups needed postoperative defibrillation, equating to $71 \%$ of dexmedetomidinetreated patients and $81 \%$ of patients in the placebo group ( $\mathrm{p}=0.56$ for overall comparison between groups). Eighteen dexmedetomidine patients and eight placebo patients needed postoperative pacing $(\mathrm{p}=0.028)$. As this study focuses on the renal effects of dexmedetomidine and hemodynamics were strictly guided by the study protocol (Table 1), hemodynamics are not reported. 


\section{Creatinine clearance}

Perioperative creatinine clearance increased in both groups during the study period (0-24-48 h), with a significant time effect $(\mathrm{p}<0.001)$ but without significant difference between the groups $(\mathrm{p}=0.93)$ (Figure 2 ). Mean maximal increases were $15.2 \%$ and $26.2 \%$ in the dexmedetomidine and placebo groups, respectively, with no significant difference between groups. The 95\% confidence intervals (CIs) for group differences were from -16.80 to $7.86 \mathrm{ml} \cdot \mathrm{min}^{-1} \cdot 1.73 \mathrm{~m}^{-2}$ in the first $24 \mathrm{~h}$ after catheter insertion and from -11.34 to $13.44 \mathrm{ml}$. $\mathrm{min}^{-1} \cdot 1.73 \mathrm{~m}^{-2}$ in the second $24 \mathrm{~h}$ (i.e. 24-48 h after catheter insertion). Analysis based on ITT population revealed that perioperative creatinine clearance (0-24-48 h) increased in both groups similarly to evaluable patients with a significant time effect $(\mathrm{p}<0.001)$. There was no significant difference between the groups ( $\mathrm{p}=$ 0.77). Mean maximal increases were $12.4 \%$ and $20.4 \%$ in the dexmedetomidine and placebo groups, respectively, with no significant difference between groups. The $95 \%$ CIs for differences between the treatment groups were from -15.28 to $8.88 \mathrm{ml} \cdot \mathrm{min}^{-1} \cdot 1.73 \mathrm{~m}^{-2}$ in the first 24 $\mathrm{h}$ after catheter insertion and from -9.05 to $15.38 \mathrm{ml}$. $\mathrm{min}^{-1} \cdot 1.73 \mathrm{~m}^{-2} 24-48 \mathrm{~h}$ after catheter insertion.

\section{Other variables of renal function}

There was no significant intergroup difference in creatinine clearance calculated at 4-h intervals (Figure 3A). Mean urinary output per $24 \mathrm{~h}$ increased from $1408 \pm$ $623 \mathrm{ml}$ before surgery to $5599 \pm 1386 \mathrm{ml}$ during the 24

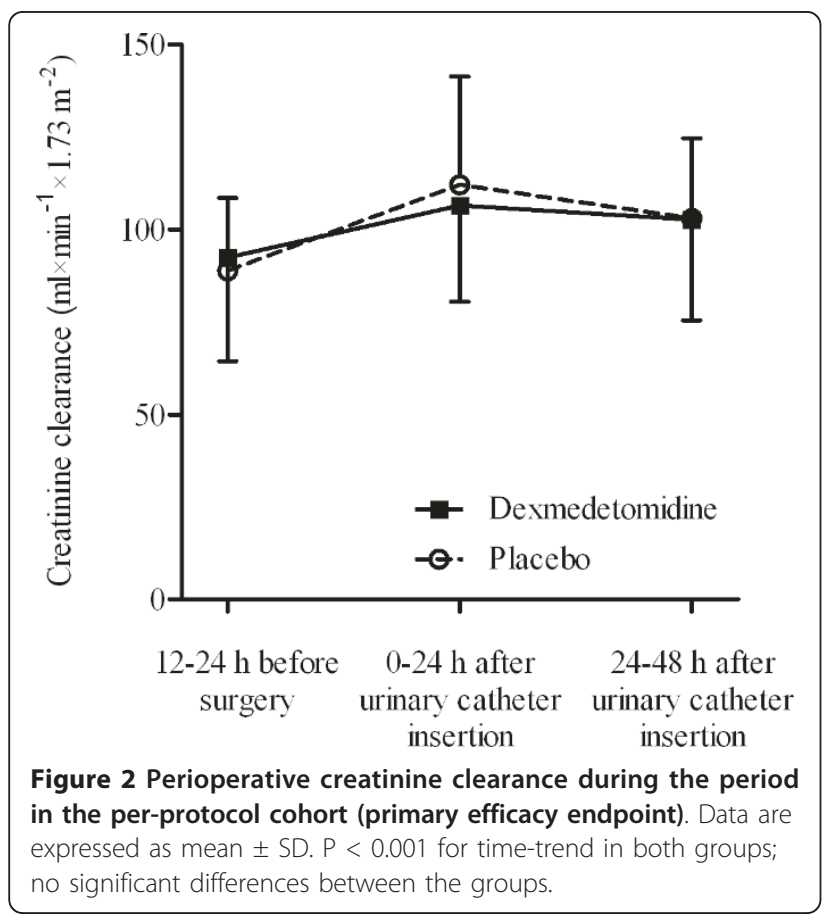

$\mathrm{h}$ following catheter insertion in the dexmedetomidine group and from $1314 \pm 487 \mathrm{ml}$ to $4497 \pm 840 \mathrm{ml}$ in the placebo group ( $\mathrm{p}<0.001$ between groups). Urinary volumes 24-48 h after catheter insertion were $2799 \pm$ $757 \mathrm{ml}$ and $2938 \pm 1037 \mathrm{ml}$, respectively ( $\mathrm{p}=0.67)$. Furosemide was administered according to the conditions specified in the protocol to stimulate urine production in 22 dexmedetomidine-treated patients and 23 placebotreated patients $(\mathrm{p}=0.32)$. The median dose was $5 \mathrm{mg}$ in both groups. Urinary output was also analyzed at 4-h intervals. In paired comparisons, the urinary outputs in the first $(0-4 \mathrm{~h})$ and third (8-12 h) fractions were significantly higher in the dexmedetomidine group when compared to placebo $(\mathrm{p}<0.05)$. The mean urinary output in the first fraction was $74 \%$ greater in the dexmedetomidine group (Figure 3B; $\mathrm{p}<0.001$ vs. placebo). Fractional sodium excretion increased several-fold in both groups during and after surgery (Figure 3D).

Perioperative $\mathrm{S}-\mathrm{K}$ and $\mathrm{S}-\mathrm{Na}$ values were quite similar in both groups. Dexmedetomidine patients had slightly higher serum electrolyte levels towards the end of follow-up (treatment-time interactions; $\mathrm{p}=0.0045$ for $\mathrm{S}-\mathrm{K}$; $\mathrm{p}<0.001$ for $\mathrm{S}-\mathrm{Na}$ ) without the effect of time or treatment. Likewise, no treatment effect or effect of time in the ANOVA was noticed, but there was a treatmenttime interaction for U-K ( $\mathrm{p}=0.0027)$. No effect of time, treatment or treatment-time interaction for U-Na was found. There was also a treatment effect on U-K ( $\mathrm{p}=$ 0.0027 dexmedetomidine vs. placebo) at $48 \mathrm{~h}$ after catheter removal but not at earlier times.

Perioperative S-Crea was relatively stable, with no significant differences between the groups (Figure 3C). UCrea first fell by $>80 \%$ from baseline in both groups thereafter gradually recovering with an overall time effect $(p<0.001)$. There were no overall treatment effect between the groups in S-Osmol and U-osmol (Table 3). Time-dependent changes in blood and urine concentrations of glucose were seen in both groups $(p<0.001)$.

\section{Plasma catecholamines}

$\mathrm{CMH}$ test showed a significant difference between the groups in perioperative epinephrine concentrations $(\mathrm{p}<$ 0.001 ) although the concentrations were quite similar in both treatment groups (Figure 4). Plasma norepinephrine concentrations were significantly smaller in the dexmedetomidine-treated patients $(\mathrm{p}<0.001$; Figure 4$)$.

\section{Discussion}

Although urinary output increased and plasma norepinephrine decreased in these relatively low-risk elective CABG patients during dexmedetomidine treatment, we were not able to demonstrate a significant dexmedetomidine-related benefit in terms of renal function as evaluated with creatinine clearance. In spite of the fact that 
A
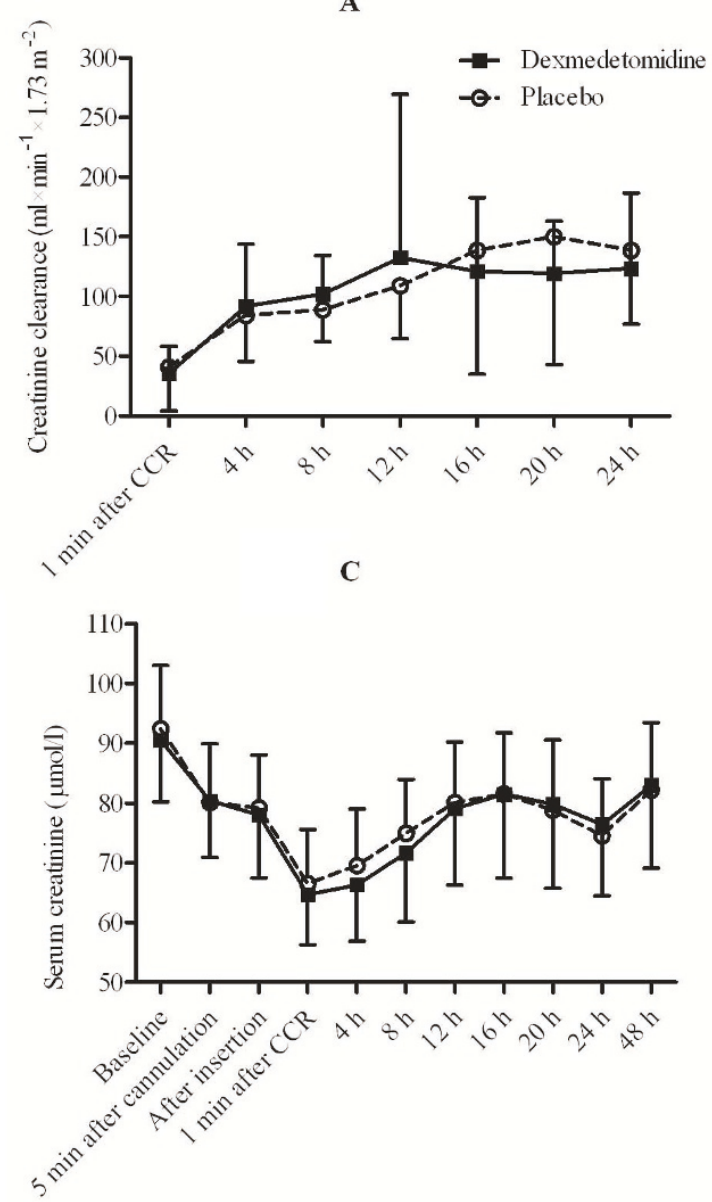

B

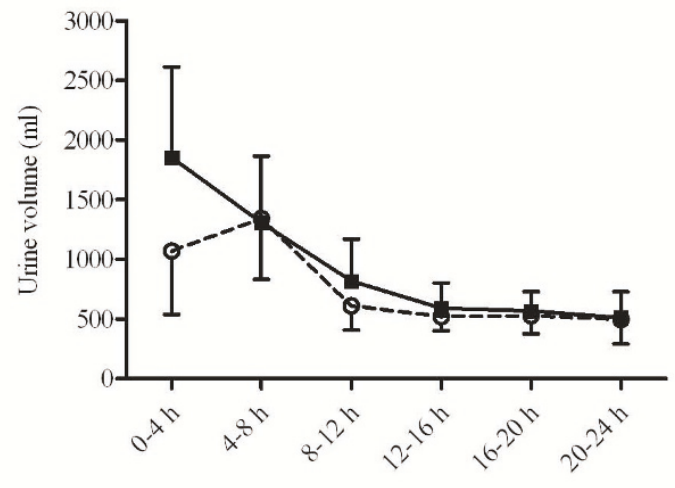

D

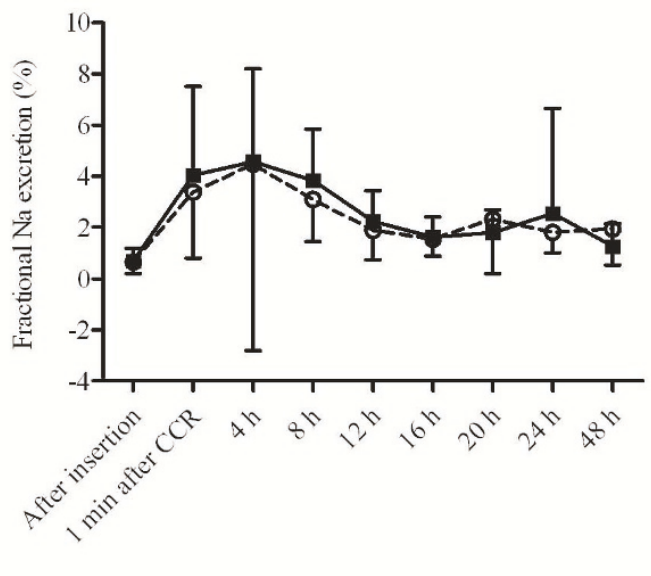

Figure 3 Perioperative renal parameters. Creatinine clearance (A) and urinary output (B) in 4-h episodes. Serum creatinine (C) and fractional sodium excretion (D) during the perioperative period. Data are expressed as mean $\pm S D$. CCR $=$ cross clamp removal.

the targeted number of evaluable patients was not reached, the confidence intervals for group differences in creatinine clearance clearly demonstrate that our sample size was adequate for a negative (no difference) conclusion. Because of smaller than anticipated variance in the primary endpoint, we can exclude a larger than
$15 \%$ difference between the groups. We argue that such a small difference would hardly have clinical significance. It should also be noted that the protocol stipulated the attainment and maintenance of a dexmedetomidine plasma level of $0.6 \mathrm{ng} / \mathrm{ml}$, which is at the lower end of the preferred therapeutic concentration

Table 3 Serum and urine osmolality

\begin{tabular}{lcccc}
\hline & \multicolumn{2}{c}{ Dexmedetomidine } & \multicolumn{2}{c}{ Placebo } \\
\hline & S-Osmol mosm/kg & U-Osmol mosm/kg & S-Osmol mosm/kg & U-Osmol mosm/kg \\
\cline { 2 - 5 } 5 min after cannulation & $291 \pm 4$ & $583 \pm 178$ & $292 \pm 4$ & $625 \pm 152$ \\
1 min after cross clamp removal & $295 \pm 4$ & $326 \pm 93$ & $293 \pm 5$ & $353 \pm 80$ \\
24 h after urinary catheter insertion & $296 \pm 9$ & $618 \pm 117$ & $290 \pm 7$ & $649 \pm 85$ \\
48 h after urinary catheter insertion & $294 \pm 7$ & $579 \pm 128$ & $295 \pm 19$ & $506 \pm 84$ \\
\hline
\end{tabular}

There were no significant differences between the groups, effect of time or treatment-time interaction in serum osmolality (S-Osmol). Urine osmolality (U-Osmol) initially decreased in both groups ( $p<0.001$ for time effect) without treatment effect. However, there was a significant treatment-time interaction in the ANOVA $(p=0.024)$ and in paired comparisons dexmedetomidine patients had significantly higher values $48 \mathrm{~h}$ after urinary catheter insertion $(p=0.02)$ 
A

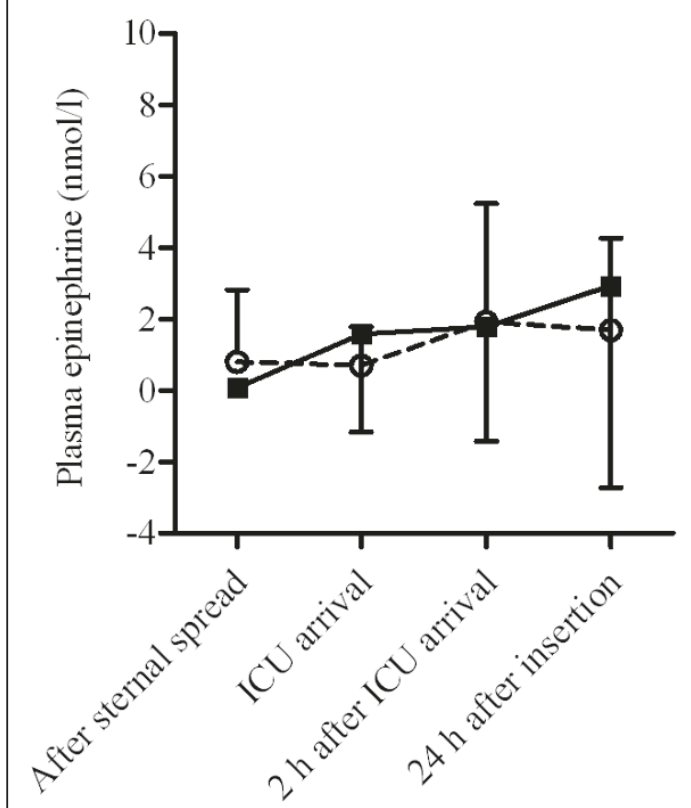

B

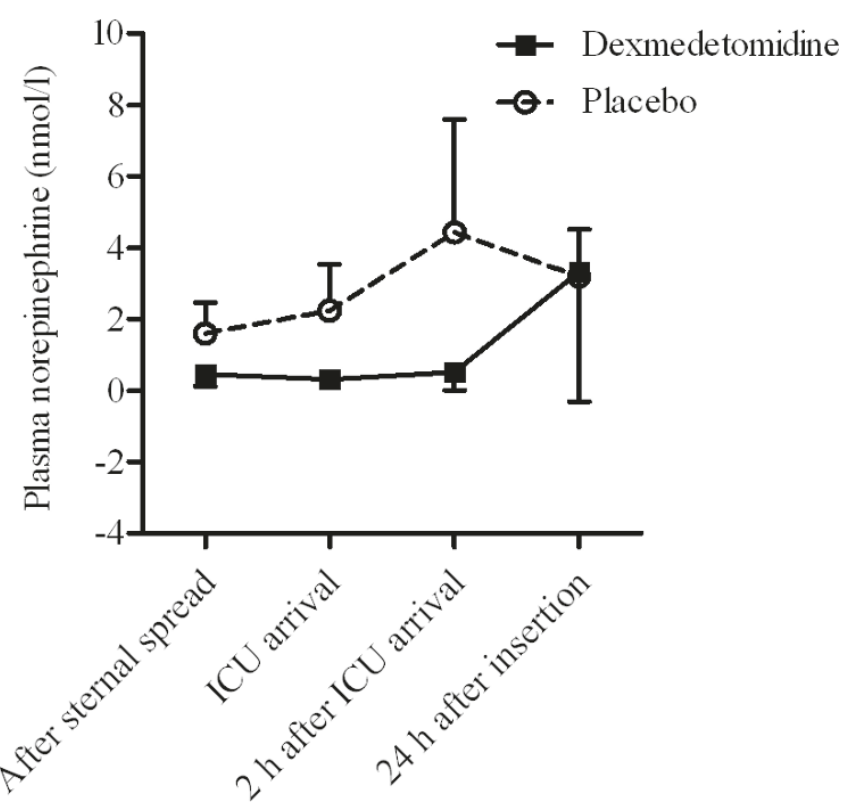

Figure 4 Plasma epinephrine and norepinephrine concentrations during the perioperative period. Data are expressed as mean \pm SD.

[13]. Nevertheless, we did not measure the true individual plasma concentrations nor did we consider the true body weight of the patients in dose calculation. Thus, there has likely been some interindividual differences in the true plasma concentrations. Further trials may be warranted to examine the effect of higher and weightbased dexmedetomidine dosing on indices of renal function in higher risk patients.

Postoperative AKI is a relatively rare complication of CABG but has a profoundly disadvantageous impact on short-term ( $<30$ day) prognosis. In-hospital mortality rates of $40 \%$ and more have been reported in several series of patients, compared with rates of around $1 \%$ in patients without kidney insufficiency [14-17]. Loef et al. [17] have also reported a more than 10-fold increase in short-term mortality with postoperative kidney insufficiency and, in contrast to some other investigators $[18,19]$, have linked postoperative AKI to reduced longer-term survival. A recent review endorses the contribution of AKI as an independent factor associated with substantial morbidity and mortality following cardiopulmonary bypass [7].

In the present study, creatinine clearance was determined by direct measurement. We are supportive of assertion of Holzmann and colleaques that indices of clearance may be preferable to serum creatinine levels as an indicator of renal function [20]. Others have advocated markers such as cystatin $\mathrm{C}$ as an alternative means of monitoring renal function [21]. Estimation of glomerular filtration rate might also be considered as it is part of the proposed RIFLE (risk, injury, failure, loss and end stage kidney disease) classification for determination of AKI [22]. We can state that according to urinary output and serum creatinine, there were no patients fulfilling the definition of AKI according to RIFLE in the present study.

Renal effects of alpha ${ }_{2}$-adrenergic agonists in clinical settings have not been studied thoroughly so far. Pretreatment with the archetypal alpha ${ }_{2}$-adrenergic agonists, clonidine, has shown preventive effects of renal function expressed as creatinine clearance after cardiac surgery [10]. Nevertheless, clonidine is a less selective alpha $_{2}$-adrenergic agonist than dexmedetomidine and has somewhat different pharmacodynamic profile [1].

Attenuated response of sympathetic nervous system to CABG has been suggested as a potential benefit of alpha $_{2}$-adrenergic agonists. Our results regarding norepinephrine support this assumption as plasma norepinephrine was reduced at various time points during the study. However, these indications of reduced sympathetic activity might have also an influence on the greater blood loss in the dexmedetomidine group compared to the placebo group, since high adrenergic output favours thrombosis. On the other hand, the relatively low number of patients and the nature of the surgery might also predispose evaluation of blood loss to type I error. More postoperative pacing was needed in dexmedetomidine group which most probably is 
attributable to the direct effect of dexmedetomidine on cardiac conduction times [23].

The enhancement of urinary output with dexmedetomidine during the first $24 \mathrm{~h}$ after catheter insertion is favourable for dexmedetomidine, though it does not necessarily indicate a preserved renal function. Nevertheless, there was an increase of creatinine clearance from baseline in both groups and the increase was $11 \%$ higher in the placebo group, though this difference did not reach statistical significance. The increase seen in both treatment groups in creatinine clearance might have been an artifact resulting from diurnal variation [24], as baseline creatinine clearance was usually determined from 12-h night time urine samples rather than from a 24-h sample. Eventual problems in spontaneous voiding might also have resulted in systematic but likely similar underestimation of baseline creatinine clearance in both groups. Increased urine output is a recognized property of dexmedetomidine and demonstrated already earlier in patients undergoing CABG by us [3] and more recently by others in patients undergoing thoracotomy [25]. The diuretic action of dexmedetomidine evident also in the present study is consistent with sympatholysis-attenuated sodium reabsorption in tubular cells via alpha $_{2}$-adrenergic action [26]. We did not however, control or record fluid administration at the regular ward during the second postoperative day. This may have added irregularities in individual fluid management and thus urine output during that period.

The fact that we included patients at a relatively low risk of AKI may limit the interpretation of the results. In addition, we had a high drop-out rate of 21 patients due to the complexity of the study protocol. Nevertheless, all patients were included in the ITT analyses for the main end-point which were essentially the same as the per-protocol analyses.

\section{Conclusions}

This study showed that the use of intravenous dexmedetomidine did not alter renal function in this cohort of relatively low-risk elective CABG patients although it was associated with an increase in urinary output as compared to placebo. Further trials are warranted to elucidate the effect of dexmedetomidine in high-risk patients.

\section{Author details}

1) Department of Anaesthesiology, Intensive Care, Emergency Care and Pain Medicine, Turku University Hospital, Turku, Finland; 2) Department of Anesthesia and Intensive Care Medicine, Helsinki University Hospital, Jorvi Hospital, Espoo, Finland; 3) Department of Anesthesiology and Intensive Care, Helsinki University Hospital, Helsinki, Finland; 4) Department of
Pharmacology, University of Turku, Turku, Finland; 5) Department of Anesthesiology, Hospital Pulssi, Turku, Finland; 6) Department of Surgery, Turku University Hospital, Turku, Finland

\section{Abbreviations}

Defined in the text where first used.

\section{Acknowledgements}

We thank doctors Anne Kuitunen, ${ }^{3}$ Mika Valtonen, ${ }^{1}$ Juha Perttilä, ${ }^{1}$ Hannu Heikkilä ${ }^{5}$ and Timo Savunen ${ }^{6}$ as members of the Dexmedetomidine in Cardiac Surgery Study Group. We also thank Hughes associates, Oxford, UK, for providing medical writing services on behalf of Orion Pharma. Hugh associates was funded by Orion Pharma.

\section{Author details}

${ }^{1}$ Department of Anaesthesiology, Intensive Care, Emergency Care and Pain Medicine, Turku University Hospital, Turku, Finland. ${ }^{2}$ Department of Anesthesia and Intensive Care Medicine, Helsinki University Hospital, Jorvi Hospital, Espoo, Finland. ${ }^{3}$ Department of Anesthesiology and Intensive Care, Helsinki University Hospital, Helsinki, Finland. ${ }^{4}$ Department of Pharmacology, University of Turku, Turku, Finland.

\section{Authors' contributions}

$\mathrm{KL}$ participated in interpretation of results and writing. $\mathrm{MH}$ participated in the design of the study, performance of the study, interpretation of results and writing. JJ participated in the design of the study, performance of the study, interpretation of results and writing. MS participated in the design of the study, performance of the study, interpretation of results and writing. HS participated in interpretation of results and writing. RA participated in the design of the study, interpretation of results and writing. The members of the Dexmedetomidine in Cardiac Surgery Study Group (AK, MV, JP, HH, and TS) participated in performance of the study, interpretation of results and writing. All authors read and approved the manuscript and gave their intellectual contribution for it.

\section{Competing interests}

This study was funded by Orion-Pharma (Finland). The institutions involved received an unlimited research grant from Orion-Pharma, but none of the investigators received individual fees for this study. Dr. Aantaa reports that he has been a paid consultant for both Orion Pharma and Abbott Laboratories, the co-developers of dexmedetomidine, and has received research grants from Orion Pharma. Dr. Aantaa is one of the three original authors of the dexmedetomidine patent "Use of dexmedetomidine for intensive care unit sedation". The worldwide patent rights have been transferred to Orion Pharma and Abbott Laboratories. Dr. Jalonen reports that he has received research grants from Orion Pharma for studies on dexmedetomidine and other drugs. Dr. Salmenperä reports that he has received research grants from Orion Pharma for studies on levosimendan. Dr. Scheinin reports that he has been a former employee and a paid consultant for Orion Pharma. Doctors Leino, Hynynen, Kuitunen, Valtonen, Perttilä, Heikkilä and Savunen declare that they have no competing interests.

Received: 11 August 2010 Accepted: 23 May 2011

Published: 23 May 2011

\section{References}

1. Aantaa $\mathrm{R}$, Jalonen J: Perioperative use of alpha2-adrenoceptor agonists and the cardiac patient. Eur J Anaesthesiol 2006, 23:361-372.

2. Aantaa R, Jaakola ML, Kallio A, Kanto J: Reduction of the minimum alveolar concentration of isoflurane by dexmedetomidine. Anesthesiology 1997, 86:1055-1060.

3. Jalonen J, Hynynen $M$, Kuitunen A, Heikkilä $H$, Perttila J, Salmenpera M, Valtonen M, Aantaa R, Kallio A: Dexmedetomidine as an anesthetic adjunct in coronary artery bypass grafting. Anesthesiology 1997, 86:331-345.

4. Lawrence CJ, De Lange S: Effects of a single pre-operative dexmedetomidine dose on isoflurane requirements and peri-operative haemodynamic stability. Anaesthesia 1997, 52:736-744. 
5. Herr DL, Sum-Ping ST, England M: ICU sedation after coronary artery bypass graft surgery: dexmedetomidine-based versus propofol-based sedation regimens. J Cardiothorac Vasc Anesth 2003, 17:576-584.

6. Venn M, Newman J, Grounds M: A phase II study to evaluate the efficacy of dexmedetomidine for sedation in the medical intensive care unit. Intensive Care Med 2003, 29:201-207.

7. Rosner MH, Portilla D, Okusa MD: Cardiac surgery as a cause of acute kidney injury: pathogenesis and potential therapies. J Intensive Care Med 2008, 23:3-18.

8. Gellai M, Ruffolo RR Jr: Renal effects of selective alpha-1 and alpha-2 adrenoceptor agonists in conscious, normotensive rats. J Pharmacol Exp Ther 1987, 240:723-728.

9. De Leeuw PW, Birkenhager WH: Alpha-adrenoceptors in the kidney. J Hypertens 1988, 6(Suppl):21-24.

10. Kulka PJ, Tryba M, Zenz M: Preoperative alpha sub 2-adrenergic receptor agonists prevent the deterioration of renal function after cardiac surgery: Results from a randomized, controlled trial. Crit Care Med 1996, 24:947-952.

11. Talke P, Richardson CA, Scheinin M, Fisher DM: Postoperative pharmacokinetics and sympatholytic effects of dexmedetomidine. Anesth Analg 1997, 85:1136-1142.

12. Scheinin M, Koulu M, Laurikainen E, Allonen H: Hypokalemia and other non-bronchial effects of inhaled fenoterol and salbutamol: A placebocontrolled dose-response study in healthy volunteers. $\mathrm{Br} J$ Clin Pharmacol 1987, 24:645-653.

13. Ebert TJ, Hall JE, Barney JA, Uhrich TD, Colinco MD: The effects of increasing plasma concentrations of dexmedetomidine in humans. Anesthesiology 2000, 93:382-394

14. Alex J, Shah R, Griffin SC, Cale AR, Cowen ME, Guvendik L: Intensive care unit readmission after elective coronary artery bypass grafting. Asian Cardiovasc Thorac Ann 2005, 13:325-329.

15. Holzmann MJ, Ahnve S, Hammar N, Jorgensen L, Klerdal K, Pehrsson K, Ivert $\mathrm{T}$ : Creatinine clearance and risk of early mortality in patients undergoing coronary artery bypass grafting. J Thorac Cardiovasc Surg 2005, 130:746-752.

16. Bove T, Calabro MG, Landoni G, Aletti G, Marino G, Crecsenzi G, Rosica C, Zangrillo $A$ : The incidence and risk of acute renal failure after cardiac surgery. J Cardiothorac Vasc Anesth 2004, 18:442-445.

17. Loef BG, Epema AH, Smilde TD, Henning RH, Ebels T, Navis G, Stegeman CA: Immediate postoperative renal function deterioration in cardiac surgical patients predicts in-hospital mortality and long-term survival. J Am Soc Nephrol 2005, 16:195-200.

18. Landoni G, Zangrillo A, Franco A, Aletti G, Roberti A, Calabro MG, Slaviero G,

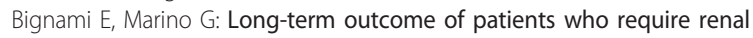
replacement therapy after cardiac surgery. Eur J Anaesthesiol 2006, 23:17-22.

19. Luckraz H, Gravenor MB, George R, Taylir S, Williams A, Ashraf S, Argamo V, Youhana A: Long and short-term outcomes in patients requiring continuous renal replacement therapy post cardiopulmonary bypass. Eur J Cardiothorac Surg 2005, 27:906-909.

20. Holzmann MJ, Ahnve S, Hammar N, Jorgensen L, Klerdal K, Pehrsson K, Ivert T: Creatinine clearance and risk of early mortality in patients undergoing coronary artery bypass grafting. J Thorac Cardiovasc Surg 2005, 130:746-752.

21. Sear JW: Kidney dysfunction in the postoperative period. $\mathrm{Br} J$ Anaesth 2005, 95:20-32.

22. Bellomo R, Ronco C, Kellum JA, Mehta RL, Palevsky P, ADQI workgroup: Acute renal failure - definition, outcome measures, animal models, fluid therapy and information technology needs: the Second International Consensus Conference of the Acute Dialysis Quality Initiative (ADQI) Group. Crit Care 2004, 8:204-212.

23. Hammer GB, Drover DR, Cao H, Jackson E, Williams GD, Ramamoorthy C, van Hare GF, Niksch A, Dubin AM: The effects of dexmedetomidine on cardiac electrophysiology in children. Anesth Analg 2008, 106:79-83.

24. Addis T, Barrett E, Poo LJ, Ureen HJ, Lippman RW: The relation between protein consumption and diurnal variations of the endogenous creatinine clearance in normal individuals. J Clin Invest 1951, 30:206-209.

25. Frumento RJ, Logginidou HG, Wahlander S, Wagener G, Playford HR, Sladen RN: Dexmedtomidine infusion is associated with enhanced renal function after thoracic surgery. J Clin Anaesth 2006, 18:422-426.
26. Rouch AJ, Kudo LH, Hebert C: Dexmedetomidine inhibits osmotic water permeability in the rat cortical collecting duct. J Pharmacol Exp Ther 1997, 281:62-69.

\section{Pre-publication history}

The pre-publication history for this paper can be accessed here: http://www.biomedcentral.com/1471-2253/11/9/prepub

doi:10.1186/1471-2253-11-9

Cite this article as: Leino et al:: Renal effects of dexmedetomidine during coronary artery bypass surgery: a randomized placebocontrolled study. BMC Anesthesiology 2011 11:9.

\section{Submit your next manuscript to BioMed Central and take full advantage of:}

- Convenient online submission

- Thorough peer review

- No space constraints or color figure charges

- Immediate publication on acceptance

- Inclusion in PubMed, CAS, Scopus and Google Scholar

- Research which is freely available for redistribution

Submit your manuscript at www.biomedcentral.com/submit
Ciomed Central 